\title{
Which prognostic factors are important for long-term outcomes in symptomatic obstructive colon cancer? A multi-institutional retrospective cohort study
}

\author{
Chang Hwan Kim¹, Jung Hoon Bae², Chul Seung Lee², Seung-Rim Han², In Kyu Lee², Dosang Lee², Won Kyung Kang³, \\ Ji Hoon Kim${ }^{4}$, Bong-Hyeon Kye ${ }^{5}$, Hyeon-Min Cho ${ }^{5}$, Seong Taek Oh6 ${ }^{6}$, Sang Chul Lee ${ }^{7}$, Yoon Suk Lee² \\ 'Department of General Surgery, Seoul St. Mary's Hospital, College of Medicine, The Catholic University of Korea, Seoul, Korea \\ ${ }^{2}$ Division of Colorectal Surgery, Department of General Surgery, Seoul St. Mary's Hospital, College of Medicine, The Catholic University of Korea, Seoul, Korea \\ ${ }^{3}$ Division of Colorectal Surgery, Department of General Surgery, Yeouido St. Mary's Hospital, College of Medicine, The Catholic University of Korea, Seoul, Korea \\ ${ }^{4}$ Division of Colorectal Surgery, Department of General Surgery, Incheon St. Mary's Hospital, College of Medicine, The Catholic University of Korea, Seoul, Korea \\ ${ }^{5}$ Division of Colorectal Surgery, Department of General Surgery, St. Vincent's Hospital, College of Medicine, The Catholic University of Korea, Seoul, Korea \\ ${ }^{6}$ Division of Colorectal Surgery, Department of General Surgery, Uijeongbu St. Mary's Hospital, College of Medicine, The Catholic University of Korea, Seoul, Korea \\ ${ }^{7}$ Division of Colorectal Surgery, Department of General Surgery, Daejeon St. Mary's Hospital, College of Medicine, The Catholic University of Korea, Seoul, Korea
}

Purpose: The prognostic factors in obstructive colon cancer have not been clearly identified. We aimed to identify the prognostic factor to establish optimal treatment strategy in obstructive colon cancer.

Methods: Patients who underwent surgery for primary colon cancer in stages II and III with symptomatic obstruction from 2004 to 2010 in six hospitals were retrospectively collected. Clinicopathological and surgical outcomes were compared between stent insertion and emergent surgery group. Multiple regression analysis and survival curve analysis were used to identify the prognostic factors in symptomatic obstructive colon cancer.

Results: Among 210 patients, 168 patients (80.0\%) underwent stent insertion followed by surgery and 42 patients $(20.0 \%)$ underwent emergent surgery. Laparoscopic approach $(55.4 \%$ vs. $23.8 \%, p<0.001)$ and adequate lymph node (LN) harvest $(\geq 12)(93.5 \%$ vs. $69.0 \%, p<0.001)$ were significantly higher in stent insertion group. In multiple regression analysis, emergent surgery (hazard ratio [HR], 2.153; 95\% confidence interval [CI], 1.031-4.495), vascular invasion (HR, 6.257; 95\% CI, 2.784-14.061), and omitting adjuvant chemotherapy (HR, 3.107; 95\% CI, 1.394-6.925) were independent poor prognostic factors in 5-year overall survival, and N stage (N1: HR, 3.095; 95\% CI, 1.316-7.284; N2: HR, 4.156; 95\% CI, 1.671-10.333) was the only poor prognostic factor in 5-year disease-free survival.

Conclusion: In symptomatic obstructive colon cancer, emergent surgery, $\mathrm{N}$ stage, vascular invasion, and omission of adjuvant chemotherapy were independent poor prognostic factors. Stent insertion is suggested as the initial treatment for symptomatic obstructive colon cancer, and adjuvant chemotherapy is recommended, especially when vascular invasion or LN metastasis is confirmed.

Keywords: Colonic neoplasms, Intestinal obstruction, Self expandable metallic stents, Laparoscopy, Prognosis

This is an Open Access article distributed under the terms of the Creative Commons Attribution Non-Commercial License (http:// creativecommons.org/licenses/by-nc/4.0/) which permits unrestricted non-commercial use, distribution, and reproduction in any medium, provided the original work is properly cited.
Received May 14, 2021

Revised July 6, 2021

Accepted July 22, 2021

Corresponding author

Yoon Suk Lee

Division of Colorectal Surgery,

Department of General Surgery, Seoul St. Mary's Hospital, College of Medicine, The Catholic University of Korea, 222 Banpo-daero, Seocho-gu, Seoul 06591, Korea

Tel: +82-2-2258-6095

Fax: +82-2-2258-2282

E-mail: yslee@catholic.ac.kr ORCID:

https://orcid.org/0000-0002-1849-2774
Copyright (C) The Korean Society of Endo scopic and Laparoscopic Surgeons. 


\section{INTRODUCTION}

Obstruction is one of the complications occurring in colon cancer, and up to $29 \%$ of colon cancers present with symptomatic obstruction, resulting in poor prognosis [1]. Symptomatic obstruction needs emergent management because of the risk of bowel perforation or peritonitis. In general, there are two treatment options for obstructive colon cancer; emergent surgical procedure with or without anastomosis and bridge-to-surgery following self-expanding metallic stent (SEMS) insertion $[2,3]$.

Although some guidelines have recently been established for obstructive colon cancer, whether to perform SEMS insertion or emergent surgery remains controversial [4-7]. Recently, several studies have shown that the long-term outcome in SEMS insertion is comparable to that of emergent surgery, but the choice of treatment is still not clear because the prognostic factors of obstructive colon cancer have not been verified yet [8-12]. Identifying the prognostic factors is required to predict the long-term outcome and determine the treatment strategy. However, there are relatively few studies about prognostic risk evaluation including treatment strategies for obstructive colon cancer. The present study aimed to analyze the poor prognostic factors including both pathologic outcomes and treatment strategies in symptom- atic obstructive colon cancer.

\section{MATERIALS AND METHODS}

\section{Patient selection and study design}

Flow diagram of patient selection is demonstrated in (Fig. 1). Patients who underwent curative resection for stage II, III colon cancer from January 2004 to December 2010 in the Catholic University of Korea Medical Center (Seoul St. Mary's Hospital, Yeouido St. Mary's Hospital, Incheon St. Mary's Hospital, St. Vincent's Hospital, Uijeongbu St. Mary's Hospital, and Daejeon St. Mary's Hospital) were retrospectively reviewed with medical records. A total of 1,785 patients were identified. We excluded 1,451 patients without colonic obstruction, 63 patients who had colonic obstruction without clinical symptom, 40 patients with evidence of perforation, and 21 patients with inadequate medical information were excluded. In final, 210 patients with symptomatic obstructive colon cancer were finally enrolled in the study. All patients were followed up with routine laboratory tests, imaging evaluation including chest and abdomen computed tomography (CT), and annual colonoscopy. The follow-up was completed in December 2015.

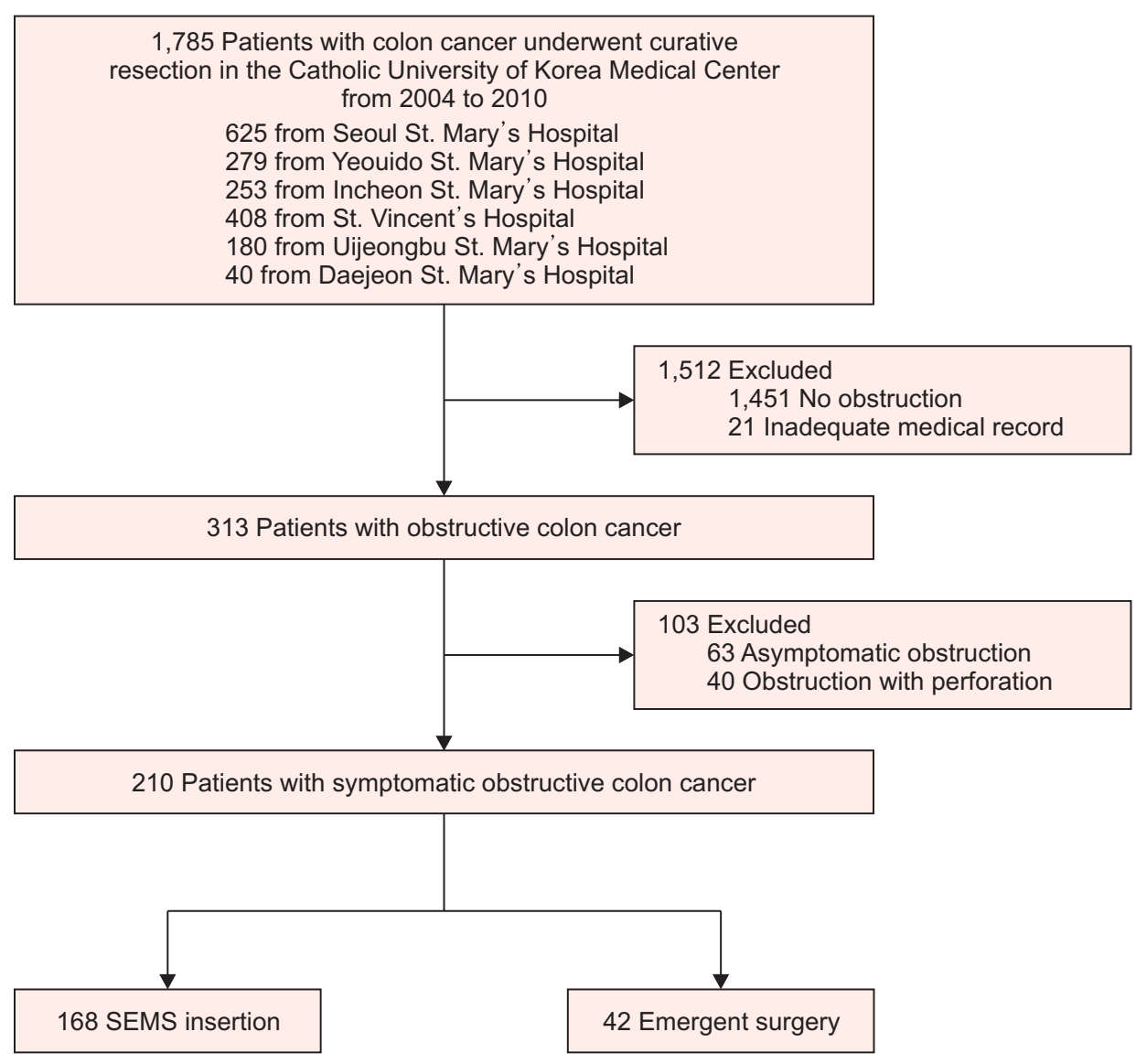

Fig. 1. Flow chart of patient's selection in symptomatic obstructive colon cancer. SEMS, self-expanding metallic stent. 
Table 1. Clinicopathological characteristics and surgical outcomes of symptomatic obstructive colon cancer

\begin{tabular}{|c|c|c|c|c|}
\hline Variable & Total & SEMS insertion & Emergent surgery & $p$ value \\
\hline Patient & $210(100)$ & $168(80.0)$ & $42(20.0)$ & \\
\hline Age (yr) & & & & 0.010 \\
\hline$\leq 65$ & $92(43.8)$ & $81(48.2)$ & $11(26.2)$ & \\
\hline$>65$ & 118 (56.2) & $87(51.8)$ & $31(73.8)$ & \\
\hline Sex & & & & 0.534 \\
\hline Male & $111(52.9)$ & $87(51.8)$ & $24(57.1)$ & \\
\hline Female & $99(47.1)$ & $81(48.2)$ & $18(42.9)$ & \\
\hline Comorbidity & & & & 0.622 \\
\hline No & $180(85.7)$ & $145(86.3)$ & 35 (83.3) & \\
\hline Yes & $30(14.3)$ & $23(13.7)$ & $7(16.7)$ & \\
\hline Tumor location & & & & $<0.001$ \\
\hline Right sided & $46(21.9)$ & $27(16.1)$ & $19(45.2)$ & \\
\hline Left sided & 164 (78.1) & $141(83.9)$ & $23(54.8)$ & \\
\hline \multicolumn{5}{|l|}{ Stent procedure } \\
\hline Clinical success & & $155(92.3)$ & & \\
\hline Clinical failure & & $13(7.7)$ & & \\
\hline Surgical approach & & & & $<0.001$ \\
\hline Laparoscopic & $103(49.0)$ & $93(55.4)$ & $10(23.8)$ & \\
\hline Conventional & $107(51.0)$ & $75(44.6)$ & 32 (76.2) & \\
\hline Combined resection & & & & 0.303 \\
\hline No & $176(83.8)$ & $143(85.1)$ & $33(78.6)$ & \\
\hline Yes & 34 (16.2) & $25(14.9)$ & $9(21.4)$ & \\
\hline Stoma formation & & & & 0.240 \\
\hline No & $190(90.5)$ & $154(91.7)$ & $36(85.7)$ & \\
\hline Yes & $20(9.5)$ & $14(8.3)$ & $6(14.3)$ & \\
\hline T stage $\mathrm{e}^{\mathrm{a})}$ & & & & 0.643 \\
\hline 3 & $175(83.3)$ & $141(83.9)$ & $34(81.0)$ & \\
\hline 4 & 35 (16.7) & $27(16.1)$ & $8(19.0)$ & \\
\hline $\mathrm{N}$ stage & & & & 0.046 \\
\hline 0 & 95 (45.2) & $70(41.7)$ & 25 (59.5) & \\
\hline 1 & $63(30.0)$ & $53(31.5)$ & $10(23.8)$ & \\
\hline 2 & $52(24.8)$ & $45(26.8)$ & $7(16.7)$ & \\
\hline TNM stage & & & & 0.038 \\
\hline$\|$ & 95 (45.2) & $70(41.7)$ & $25(59.5)$ & \\
\hline III & $115(54.8)$ & 98 (58.3) & $17(40.5)$ & \\
\hline LN harvest & & & & $<0.001$ \\
\hline$\geq 12$ & $186(88.6)$ & $157(93.5)$ & $29(69.0)$ & \\
\hline$<12$ & $24(11.4)$ & $11(6.5)$ & $13(31.0)$ & \\
\hline
\end{tabular}


Table 1. Continued

\begin{tabular}{|c|c|c|c|c|}
\hline Variable & Total & SEMS insertion & Emergent surgery & $p$ value \\
\hline Histologic type & & & & 0.190 \\
\hline Well/moderate & $176(83.8)$ & $138(82.1)$ & 38 (90.5) & \\
\hline Poor/Muc/Sig & $34(16.2)$ & $30(17.9)$ & $4(9.5)$ & \\
\hline Vascular invasion & & & & 0.630 \\
\hline No & $191(91.0)$ & $152(90.5)$ & $39(92.9)$ & \\
\hline Yes & $19(9.0)$ & $16(9.5)$ & $3(7.1)$ & \\
\hline Lymphatic invasion & & & & 0.188 \\
\hline No & $96(45.7)$ & $73(43.5)$ & $23(18.1)$ & \\
\hline Yes & $114(54.3)$ & $95(56.5)$ & $19(45.2)$ & \\
\hline Perineural invasion & & & & 0.143 \\
\hline No & $140(66.7)$ & $108(64.3)$ & 32 (76.2) & \\
\hline Yes & $70(33.3)$ & $60(35.7)$ & $10(23.8)$ & \\
\hline Adjuvant chemotherapy & & & & 0.006 \\
\hline Yes & $163(77.6)$ & $137(81.5)$ & $26(61.9)$ & \\
\hline No & $47(22.4)$ & $31(18.5)$ & $16(38.1)$ & \\
\hline Recurrence & & & & 0.755 \\
\hline No & $154(73.3)$ & $124(73.9)$ & $30(71.4)$ & \\
\hline Yes & $56(26.7)$ & 44 (26.2) & 12 (28.6) & \\
\hline
\end{tabular}

Data are expressed as number (\%).

SEMS, self-expanding metallic stent; LN, lymph node; Muc, mucinous adenocarcinoma; Sig, signet-ring cell carcinoma.

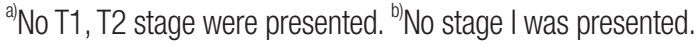

Patients' data were collected from each hospital's colon cancer patient registry including the demographic and clinicopathological characteristics, surgical outcomes, recurrence, and survival records. Patients were divided into two groups based on the initial treatment modality for the comparison analysis; SEMS insertion and emergent surgery.

The HANARO stent (M.I. Tech Corp., Ltd., Seoul, Korea) or the Niti-S stent (Taewoong Medical, Corp., Ltd., Gimpo, Korea) were used in all cases of SEMS insertion. Whether to perform SEMS insertion or emergent surgery was decided by each surgeon in consultation with an endoscopist. Complications such as perforation, stent expansion, and resolution of the bowel distension were checked serial plain abdominal films after the SEMS was inserted. Mechanical bowel preparation before surgery was performed if SEMS insertion was successful.

Oncological long-term outcomes were compared between two groups. The primary outcomes were 5-year overall survival (OS) and 5-year disease-free survival (DFS). The OS was defined as the time interval from the date of operation to the date of expire or last visit to the clinic. The DFS was defined as the time interval from the date of operation to the date of confirmation of can- cer recurrence or last visit to the clinic. Subsequently, subgroup analysis in stages II and III colon cancer, respectively.

\section{Definitions}

We defined symptomatic obstructive colon cancer as pathological confirmation of adenocarcinoma with clinical symptom of obstruction (abdominal distention, pain, tenderness, and no stool passage) and radiological finding of obstruction in CT scan or endoscopic finding of obstruction with failure of passing through tumor lesion. The right colon was defined as the cecum, ascending colon, hepatic flexure colon, and transverse colon, while the left colon was defined as the splenic flexure colon, descending colon, sigmoid colon, and rectosigmoid colon above the peritoneal reflection. The clinical success of SEMS insertion was defined as performing mechanical bowel preparation following the resolution of bowel distension. On the other hand, clinical failure was defined as the inability to perform bowel preparation due to unresolved obstruction and bowel perforation that occurred during or immediately after stent insertion. 


\section{Statistical analysis}

The comparison for categorical variables was analyzed with the chi-square or Fisher exact test. The univariate prognostic significance of variables was determined using the Cox proportional hazard model. Variables resulted as significantly related to the survival rate in univariate analysis were consequently explored in multivariate analysis employing the Cox multiple regression model. Survival analyses were calculated using the Kaplan-Meier method and comparisons of survival curves were performed using the log-rank test. Significant value was defined as a $p$ value less than 0.05. All statistical analyses were performed using IBM SPSS for Windows (version 24.0; IBM Corp., Armonk, NY, USA).

\section{RESULTS}

A total of 210 patients were included in this study. The median follow-up duration was 44 months with interquartile range of 17 to 61 months. The clinicopathological characteristics and surgical outcomes were compared in two groups and summarized in Table 1. The mean age of the patients was $65.8 \pm 12.4$ years and male-to-female ratio was 1.1:1. Among 210 patients, 168 patients (80.0\%) were initially treated with SEMS insertion followed by elective surgery and 42 patients (20.0\%) were treated with emergent surgery. Clinical success rate of SEMS insertion was 92.3\%, and the failure of SEMS insertion were observed in 13 patients (7.8\%). The bowel decompression after SEMS insertion was done in all cases. Older age $(51.8 \%$ vs. $73.8 \%, p=0.001)$ was associated with emergent surgery group. The rate of left-sided colon cancer $(83.9 \%$ vs. $54.8 \%, p<0.001)$, laparoscopic approach $(55.4 \%$ vs. $23.8 \%, p<0.001$ ), and adequate lymph node (LN) harvest number more than $12(93.5 \%$ vs. $69.0 \%, p<0.001)$ were significantly higher in SEMS insertion group than emergent surgery group. In pathological finding, $\mathrm{N}$ stage $(\mathrm{N} 1,31.5 \%$ vs. $23.8 \%$; $\mathrm{N} 2,26.8 \%$ vs. $16.7 \% ; p=0.046$ ) and TNM stage (stage III, $58.3 \%$ vs. $40.5 \%$; $p=$ 0.038 ) were significantly higher in SEMS insertion group, whereas T stage, histologic type, vascular invasion, lymphatic invasion, and perineural invasion showed no significant difference. The rate of adjuvant chemotherapy $(81.5 \%$ vs. $61.9 \%, p=0.006)$ was significantly higher in SEMS insertion group, but the recurrence rate was similar in both groups.

The outcomes of the univariate and multivariate analyses that were conducted to identify significant prognostic factors for OS and DFS in symptomatic obstructive colon cancer were demonstrated in Table 2 and 3, respectively. In terms of OS, emergent surgery (hazard ratio [HR], 2.176; 95\% confidence interval [CI], $1.088-4.354 ; p=0.028$ ), vascular invasion (HR, 3.944; 95\% CI, $1.901-8.182 ; p<0.001$ ), and omitting adjuvant chemotherapy (HR, 2.462 ; 95\% CI, 1.208-5.020; $p=0.013$ ) were poor prognostic factors in univariate analysis. In multivariate analysis, emergent surgery
(HR, 2.153; 95\% CI, 1.031-4.495; $p=0.041)$, vascular invasion (HR, 6.257; 95\% CI, 2.784-14.061; $p<0.001$ ), and omitting adjuvant chemotherapy (HR, 3.107; 95\% CI, 1.394-6.925; $p=0.006$ ) were correlatively found to be poor prognostic factors. In terms of DFS, $\mathrm{N}$ stage (N1: HR, 3.112; 95\% CI, 1.490-6.498; $p=0.003$; N2: HR, 4.862; 95\% CI, 2.389-9.896; $p<0.001$ ), vascular invasion (HR, 3.102; 95\% CI, 1.602-6.005; $p=0.001)$, lymphatic invasion (HR, 2.397; 95\% CI, $1.342-4.282 ; p=0.003$ ), and perineural invasion (HR, 1.811; $95 \%$ CI, 1.069-3.071; $p=0.027$ ) were poor prognostic factors in univariate analysis. In multivariate analysis, $\mathrm{N}$ stage (N1: HR, 3.095; 95\% CI, 1.316-7.284; $p=0.010$; N2: HR, 4.156; 95\% CI, 1.671-10.333; $p=0.002$ ) was the only poor prognostic factor.

Subgroup univariate analysis of OS and DFS in stage II and stage III were represented in Supplementary Table 1 and 2, respectively, and multivariate analyses of subgroups were summarized in Table 4. In stage II colon cancer, omitting adjuvant chemotherapy was the independent poor prognostic factor $(\mathrm{HR}$, 3.133; 95\% CI, 1.013-9.689; $p=0.047$ ) for OS. In stage III colon cancer, LN harvest less than 12 (HR, 5.166; 95\% CI, 1.471-18.141; $p$ $=0.010)$ and vascular invasion (HR, 4.790; 95\% CI, 2.064-11.135; $p<0.001)$ were found as poor prognostic factors for OS, and vascular invasion (HR, 4.790; 95\% CI, 1.092-4.268; $p=0.027$ ) was found to be the poor prognostic factor for DFS.

Survival analyses using the Kaplan-Meier curve are shown in (Fig. 2). The survival rate was analyzed using the prognostic factors defined in multivariate analysis as the dependent variable; emergent surgery, $\mathrm{N}$ stage, vascular invasion, and omitting adjuvant chemotherapy. The 5-year OS rates were $85.7 \%$ and $71.4 \%$ in SEMS insertion and emergent surgery, respectively $(p=0.024)$. In $\mathrm{N}$ stage, the 5 -year DFS rates were $88.4 \%, 68.3 \%$, and $53.8 \%$ in N0, N1, and N2, respectively ( $p<0.001)$. The 5 -year OS rates in noninvasion and vascular invasion were $86.4 \%$ and $47.4 \%$, respectively $(p<0.001)$. The 5 -year OS rates in performing and omitting adjuvant chemotherapy were $84.7 \%$ and $76.6 \%$, respectively ( $p=$ $0.010)$.

\section{DISCUSSION}

In this study, we have identified the prognostic factors for symptomatic obstructive colon cancer. Emergent surgery rather than SEMS insertion, presence of vascular invasion, and omission of adjuvant chemotherapy were the prognostic factors to lower the survival rates, where higher $\mathrm{N}$ stage appeared to be the significant prognostic factor for recurrence. Regarding SEMS insertion compared to emergent surgery, laparoscopic approach was more available and adequate $\mathrm{LN}$ dissection was more performed.

When emergent surgery is performed for obstructive colon cancer, laparotomy is more considered for the reason that severe bowel dilatation is present [11]. Our study also showed that emergent surgery had a higher rate of laparotomy approach than 
Table 2. Univariate and multivariate analysis of overall survival in symptomatic obstructive colon cancer

\begin{tabular}{|c|c|c|c|c|c|}
\hline \multirow{2}{*}{ Variable } & \multirow{2}{*}{$\begin{array}{c}\text { Total }^{\mathrm{a})} \\
(\mathrm{n}=210)\end{array}$} & \multicolumn{2}{|c|}{ Univariate } & \multicolumn{2}{|c|}{ Multivariate } \\
\hline & & HR (95\% Cl) & $p$ value & $\mathrm{HR}(95 \% \mathrm{Cl})$ & $p$ value \\
\hline \multicolumn{6}{|l|}{ Age (yr) } \\
\hline$\leq 65$ & $92(43.8)$ & Reference & & & \\
\hline$>65$ & $118(56.2)$ & $1.465(0.746-2.876)$ & 0.265 & & \\
\hline \multicolumn{6}{|l|}{ Sex } \\
\hline Male & $111(52.9)$ & Reference & & & \\
\hline Female & $99(47.1)$ & $0.670(0.343-1.311)$ & 0.242 & & \\
\hline \multicolumn{6}{|l|}{ Initial treatment } \\
\hline SEMS insertion & $168(80.0)$ & Reference & & Reference & \\
\hline Emergent & $42(20.0)$ & $2.176(1.088-4.354)$ & 0.028 & $2.153(1.031-4.495)$ & 0.041 \\
\hline \multicolumn{6}{|l|}{ Tumor location } \\
\hline Right sided & $46(21.9)$ & Reference & & & \\
\hline Left sided & $164(78.1)$ & $0.806(0.367-1.771)$ & 0.591 & & \\
\hline \multicolumn{6}{|l|}{ Surgical approach } \\
\hline Laparoscopic & $103(49.0)$ & Reference & & & \\
\hline Conventional & $107(51.0)$ & $1.366(0.835-3.193)$ & 0.152 & & \\
\hline \multicolumn{6}{|l|}{ T stage } \\
\hline 3 & $175(83.3)$ & Reference & & & \\
\hline 4 & $20(9.5)$ & $1.442(0.657-3.165)$ & 0.361 & & \\
\hline \multicolumn{6}{|l|}{ N stage } \\
\hline 0 & $95(45.2)$ & Reference & & & \\
\hline 1 & $63(30.0)$ & $1.356(0.607-3.028)$ & 0.458 & & \\
\hline 2 & $52(24.8)$ & $1.756(0.801-3.851)$ & 0.160 & & \\
\hline \multicolumn{6}{|l|}{ LN harvest } \\
\hline$\geq 12$ & $186(88.6)$ & Reference & & & \\
\hline$<12$ & $24(11.4)$ & $2.118(0.880-5.101)$ & 0.094 & & \\
\hline \multicolumn{6}{|l|}{ Histologic type } \\
\hline Well/moderate & $176(83.8)$ & Reference & & & \\
\hline Poor/Muc/Sig & 34 (16.2) & $1.299(0.540-3.124)$ & 0.559 & & \\
\hline \multicolumn{6}{|l|}{ Vascular invasion } \\
\hline No & $191(91.0)$ & Reference & & Reference & \\
\hline Yes & $19(9.0)$ & 3.944 (1.901-8.182) & $<0.001$ & 6.257 (2.784-14.061) & $<0.001$ \\
\hline \multicolumn{6}{|c|}{ Lymphatic invasion } \\
\hline No & $96(45.7)$ & Reference & & & \\
\hline Yes & $114(54.3)$ & $1.831(0.915-3.663)$ & 0.088 & & \\
\hline \multicolumn{6}{|c|}{ Perineural invasion } \\
\hline No & $140(66.7)$ & Reference & & & \\
\hline Yes & 70 (33.3) & $1.394(0.712-2.726)$ & 0.332 & & \\
\hline \multicolumn{6}{|c|}{ Adjuvant chemotherapy } \\
\hline Yes & $163(77.6)$ & Reference & & Reference & \\
\hline No & $47(22.4)$ & $2.462(1.208-5.020)$ & 0.013 & 3.107 (1.394-6.925) & 0.006 \\
\hline
\end{tabular}

$\mathrm{HR}$, hazard ratio; $\mathrm{Cl}$, confidence interval; SEMS, self-expanding metallic stent; LN, lymph node; Muc, mucinous adenocarcinoma; Sig, signet-ring cell carcinoma.

${ }^{a}$ Number (\%). 
Table 3. Univariate and multivariate analysis of disease-free survival in symptomatic obstructive colon cancer

\begin{tabular}{|c|c|c|c|c|c|}
\hline \multirow{2}{*}{ Variable } & \multirow{2}{*}{$\begin{array}{c}\text { Total }^{\mathrm{a})} \\
(\mathrm{n}=210)\end{array}$} & \multicolumn{2}{|c|}{ Univariate } & \multicolumn{2}{|c|}{ Multivariate } \\
\hline & & $\mathrm{HR}(95 \% \mathrm{Cl})$ & $p$ value & $\mathrm{HR}(95 \% \mathrm{Cl})$ & $p$ value \\
\hline \multicolumn{6}{|l|}{ Age (yr) } \\
\hline$\leq 65$ & $92(43.8)$ & Reference & & & \\
\hline$>65$ & 118 (56.2) & $1.250(0.736-2.214)$ & 0.409 & & \\
\hline \multicolumn{6}{|l|}{ Sex } \\
\hline Male & $111(52.9)$ & Reference & & & \\
\hline Female & $99(47.1)$ & $0.873(0.515-1.479)$ & 0.613 & & \\
\hline \multicolumn{6}{|l|}{ Initial treatment } \\
\hline SEMS insertion & $168(80.0)$ & Reference & & & \\
\hline Emergent & $42(20.0)$ & $1.248(0.659-2.365)$ & 0.497 & & \\
\hline \multicolumn{6}{|l|}{ Tumor location } \\
\hline Right sided & $46(21.9)$ & Reference & & & \\
\hline Left sided & $164(78.1)$ & $0.787(0.423-1.465)$ & 0.450 & & \\
\hline \multicolumn{6}{|l|}{ Surgical approach } \\
\hline Laparoscopic & $103(49.0)$ & Reference & & & \\
\hline Conventional & $107(51.0)$ & $1.486(0.872-2.532)$ & 0.146 & & \\
\hline \multicolumn{6}{|l|}{ T stage } \\
\hline 3 & $175(83.3)$ & Reference & & & \\
\hline 4 & $20(9.5)$ & 1.617 (0.883-2.962) & 0.119 & & \\
\hline \multicolumn{6}{|l|}{ N stage } \\
\hline 0 & $95(45.2)$ & Reference & & Reference & \\
\hline 1 & $63(30.0)$ & $3.112(1.490-6.498)$ & 0.003 & 3.095 (1.316-7.284) & 0.010 \\
\hline 2 & $52(24.8)$ & 4.862 (2.389-9.896) & $<0.001$ & $4.156(1.671-10.333)$ & 0.002 \\
\hline \multicolumn{6}{|l|}{ LN harvest } \\
\hline$\geq 12$ & $186(88.6)$ & Reference & & & \\
\hline$<12$ & $24(11.4)$ & $0.751(0.272-2.078)$ & 0.581 & & \\
\hline \multicolumn{6}{|l|}{ Histologic type } \\
\hline Well/moderate & $176(83.8)$ & Reference & & & \\
\hline Poor/Muc/Sig & 34 (16.2) & $1.199(0.587-2.446)$ & 0.619 & & \\
\hline \multicolumn{6}{|l|}{ Vascular invasion } \\
\hline No & $191(91.0)$ & Reference & & Reference & \\
\hline Yes & $19(9.0)$ & $3.102(1.602-6.005)$ & 0.001 & $1.750(0.810-3.777)$ & 0.154 \\
\hline \multicolumn{6}{|l|}{ Lymphatic invasion } \\
\hline No & $96(45.7)$ & Reference & & Reference & \\
\hline Yes & $114(54.3)$ & 2.397 (1.342-4.282) & 0.003 & $0.934(0.442-1.975)$ & 0.859 \\
\hline \multicolumn{6}{|c|}{ Perineural invasion } \\
\hline No & $140(66.7)$ & Reference & & Reference & \\
\hline Yes & 70 (33.3) & $1.811(1.069-3.071)$ & 0.027 & $1.176(0.652-2.124)$ & 0.590 \\
\hline \multicolumn{6}{|c|}{ Adjuvant chemotherapy } \\
\hline Yes & $163(77.6)$ & Reference & & & \\
\hline No & 47 (22.4) & 1.319 (0.665-2.617) & 0.429 & & \\
\hline
\end{tabular}

HR, hazard ratio; Cl, confidence interval; SEMS, self-expanding metallic stent; LN, lymph node; Muc, mucinous adenocarcinoma; Sig, signet-ring cell carcinoma.

${ }^{\text {a) }}$ Number (\%) 
Table 4. Multivariate analysis of OS and DFS in symptomatic obstructive colon cancer stage II and stage III

\begin{tabular}{|c|c|c|c|c|c|c|c|c|c|c|}
\hline \multirow{3}{*}{ Variable } & \multirow{3}{*}{$\begin{array}{c}\text { Total } \\
(n=95)\end{array}$} & \multicolumn{4}{|c|}{ Stage II } & \multirow{3}{*}{$\begin{array}{c}\text { Total } \\
(n=115)\end{array}$} & \multicolumn{4}{|c|}{ Stage III } \\
\hline & & \multicolumn{2}{|l|}{ OS } & \multicolumn{2}{|l|}{ DFS } & & \multicolumn{2}{|l|}{ OS } & \multicolumn{2}{|l|}{ DFS } \\
\hline & & $\begin{array}{c}\mathrm{HR} \\
(95 \% \mathrm{Cl})\end{array}$ & $p$ value & $\begin{array}{c}\mathrm{HR} \\
(95 \% \mathrm{Cl})\end{array}$ & $p$ value & & $\begin{array}{c}\mathrm{HR} \\
(95 \% \mathrm{Cl})\end{array}$ & $p$ value & $\begin{array}{c}\mathrm{HR} \\
(95 \% \mathrm{Cl})\end{array}$ & $p$ value \\
\hline \multicolumn{11}{|l|}{ Initial treatment } \\
\hline SEMS insertion & $70(73.7)$ & Reference & & Reference & & & & & & \\
\hline Emergent & $25(26.3)$ & $\begin{array}{c}2.092 \\
(0.684-6.400)\end{array}$ & 0.196 & $\begin{array}{c}2.702 \\
(0.808-9.040)\end{array}$ & 0.107 & & & & & \\
\hline \multicolumn{11}{|l|}{ Surgical approach } \\
\hline Laparoscopic & $41(43.2)$ & & & Reference & & & & & & \\
\hline Conventional & $54(56.8)$ & & & $\begin{array}{c}6.309 \\
(0.782-50.923)\end{array}$ & 0.084 & & & & & \\
\hline \multicolumn{11}{|l|}{ LN harvest } \\
\hline$\geq 12$ & & & & & & 108 (93.9) & Reference & & & \\
\hline$<12$ & & & & & & $7(6.1)$ & $\begin{array}{c}5.166 \\
(1.471-18.141)\end{array}$ & 0.010 & & \\
\hline \multicolumn{11}{|l|}{ Vascular invasion } \\
\hline No & & & & & & $97(84.3)$ & Reference & & Reference & \\
\hline Yes & & & & & & $18(15.7)$ & $\begin{array}{c}4.790 \\
(2.061-11.135)\end{array}$ & $<0.001$ & $\begin{array}{c}2.159 \\
(1.092-4.268)\end{array}$ & 0.027 \\
\hline \multicolumn{11}{|c|}{ Adjuvant chemotherapy } \\
\hline Yes & $67(70.5)$ & Reference & & & & & & & & \\
\hline No & $28(29.5)$ & $\begin{array}{c}3.133 \\
(1.013-9.689)\end{array}$ & 0.047 & & & & & & & \\
\hline
\end{tabular}

OS, overall survival; DFS, disease-free survival; HR, hazard ratio; Cl, confidence interval; SEMS, self-expanding metallic stent; LN, lymph node.

SEMS insertion $(76.2 \%$ vs. $44.6 \%, p<0.001)$. From previous studies, laparoscopic approach is known to have advantages in postoperative complications and morbidities when compared to open surgery [13-15]. In the aspect of the oncologic outcome, one metaanalysis has analyzed that adequate $\mathrm{LN}$ dissection was more performed in laparoscopy [15]. With the higher rate of laparoscopy, SEMS insertion also showed a higher rate of adequate LN harvest in our results $(93.5 \%$ vs. $69.0 \%, p<0.001)$. Furthermore, the time interval between SEMS insertion and followed surgery allows for recovery of nutritional status and resolution of bowel dilatation, which improves the postoperative outcome [16]. For these reasons, it is interpreted that emergent surgery rather than SEMS insertion appeared to be the risk factor for symptomatic obstructive colon cancer.

SEMS insertion has been reported to have superior short-term outcomes such as primary anastomosis rate and postoperative complications, as well as comparable long-term oncological outcomes compared to conventional emergent surgery [2,8-12]. Our study result showed a correlative outcome in 5-year OS rate $(58.7 \%$ vs. $71.4 \%, p=0.024)$. On the contrary, some studies reported that high local recurrence rates in SEMS insertion [17-21]. Sloothaak et al. [17] demonstrated a randomized controlled trial which resulted in the tendency of a higher rate of recurrence in emergent surgery group (4-year DFS rates, $49 \%$ vs. $30 \%$; $p=0.149$ ). Silent perforation, which is reported to occur up to $20 \%$ in SEMS insertion, or mechanical pressure induced by the metallic stent may be the reasons for tumor dissemination to increase local recurrence [22-24]. According to our study results, SEMS insertion showed similar rate of 5-year DFS and recurrence compared to those of emergent surgery (5-year DFS rate: $74.4 \%$ vs. $71.4 \%, p=0.464$; recurrence: $26.2 \%$ vs. $28.6 \%, p=0.755$ ). If survival is more favorable without the risk of recurrence, we can consider SEMS insertion as the choice of the treatment in symptomatic obstructive colon cancer more safely.

One of the prognostic factors for symptomatic obstructive colon cancer found in our results was the presence of vascular 
A

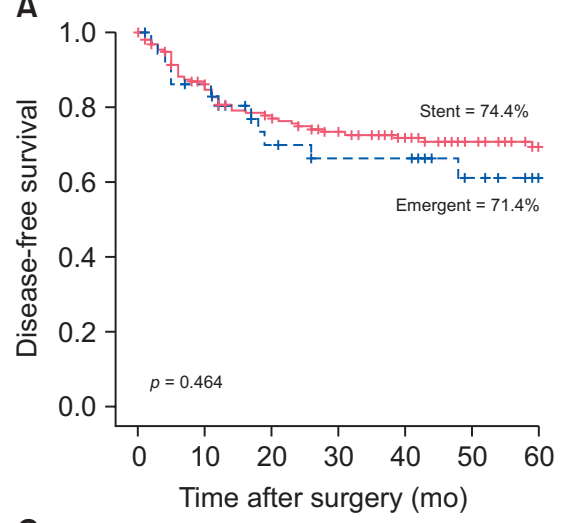

C

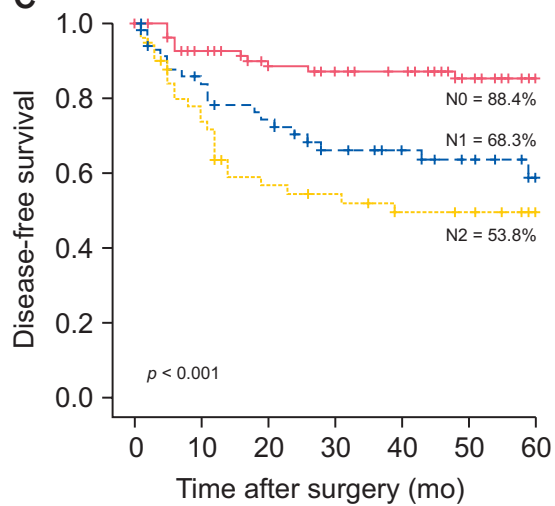

E

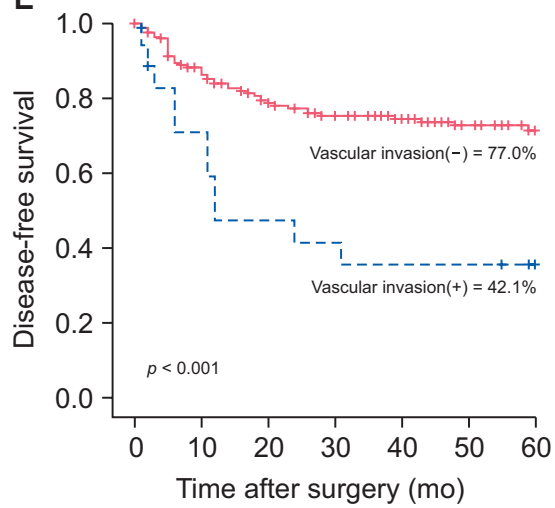

G

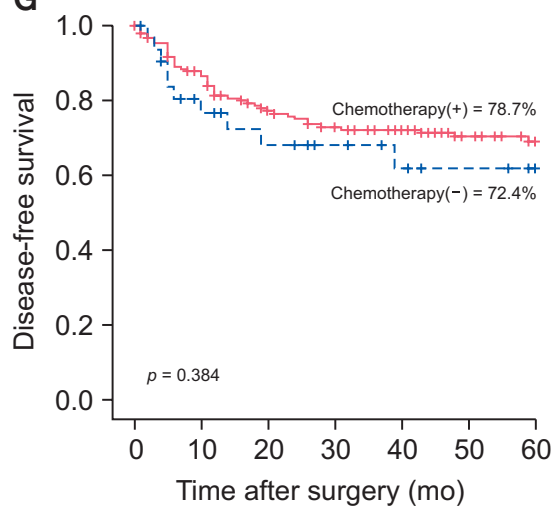

B

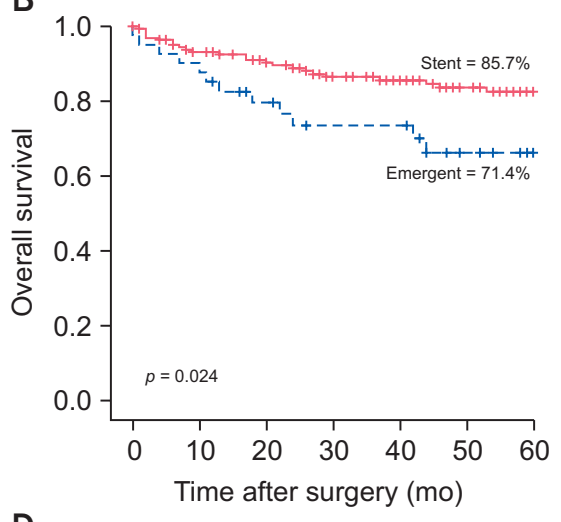

D

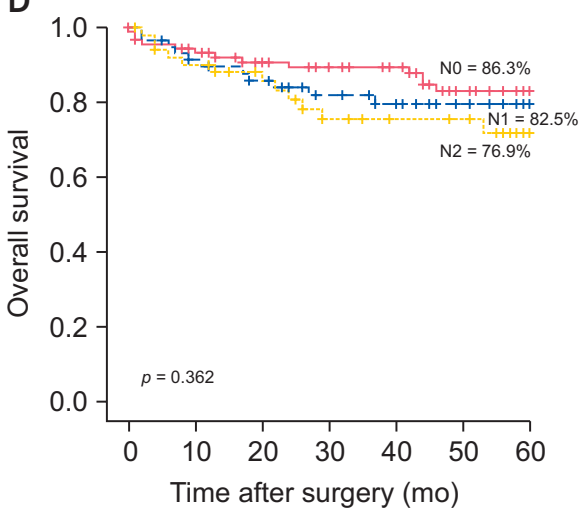

$\mathrm{F}$

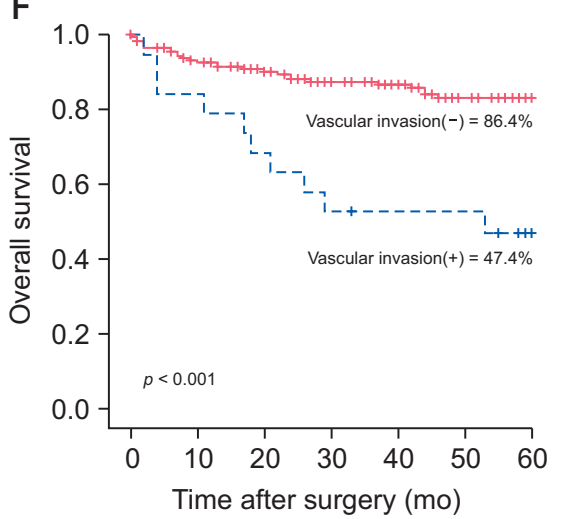

$\mathrm{H}$

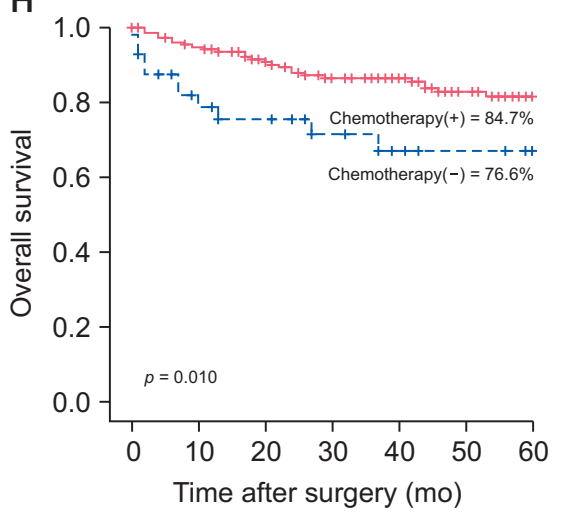

Fig. 2. Survival curves of disease-free survival and overall survival in symptomatic obstructive colon cancer for prognostic factor of initial treatment (A, B), N stage $(C, D)$, vascular invasion $(E, F)$, and adjuvant chemotherapy $(G, H)$. 
invasion. In recent, the significance of vascular invasion in colon cancer has been emphasized that its impact on prognosis is comparable to LN status ( $\mathrm{N}$ stage). Qwaider et al. [25] stated that stage II colon cancer with extramural vascular invasion had worse OS than stage III colon cancer without vascular invasion (mean survival time, $94 \pm 8$ months vs. $127 \pm 4$ months; $p$ $<0.001$ ), and Leijssen et al. [26] showed a similar result in 5-year disease-specific survival rate $(77.0 \%$ vs. $85.5 \%, p=0.021)$. In our data, stage II group had only one patient with vascular invasion without recurrence or death in 5 years. Vascular invasion in stage III group was found to be the risk factor in multivariate analysis and showed lower rate of 5 -year OS $(64.9 \%$ vs. $38.9 \%, p=0.022)$ and 5 -year DFS ( $86.6 \%$ vs. $44.4 \%, p<0.001)$. Although it cannot be regarded as a more significant prognostic factor than $\mathrm{N}$ stage, if vascular invasion is identified in symptomatic obstructive colon cancer, more aggressive treatment including adjuvant chemotherapy should be considered for a better oncological outcome.

One recent meta-analysis study reported that omitting adjuvant chemotherapy resulted in a higher recurrence rate in obstructive colon cancer [27]. Although adjuvant chemotherapy is highlighted in treatment guidelines of obstructive colon cancer, surgeons hesitate to recommend chemotherapy when patient is in old age and has poor performance status [7]. Not only found as the risk factor in entire group, omission of adjuvant chemotherapy appeared to be the risk factor for OS in stage II group and presented lower rate of 5 -year OS $(89.6 \%$ vs. $78.6 \%, p=0.014)$. Considering that obstruction in colon cancer is diagnosed higher than stage II, it can be recommended that adjuvant chemotherapy should be performed regardless of stage in symptomatic obstructive colon cancer.

Our study had some limitations. Since the study was analyzed in retrospective approach, there are possibilities of unintended selection bias. A bias was induced by the fact that each surgeon decided whether to perform SEMS insertion or emergent surgery as the initial treatment and the time interval between SEMS insertion and followed surgery. There was also a bias that the surgeon decided whether to perform adjuvant chemotherapy in consideration of patient's age and performance status. In addition, perioperative factors such as postoperative complications including leakage and infection, presence of stoma formation, and period of hospitalization were not analyzed in our study. Moreover, the lack of statistical analysis with nonobstructive colon cancer appeared to be another limitation and further research is required. However, our study has strong points that subgroup analysis dividing into stages II and III was conducted to reduce the bias, and multicenter analysis has been done to evaluate numerous, different patients.

In conclusion, this study demonstrated that $\mathrm{N}$ stage, emergent surgery, vascular invasion, and omitting adjuvant chemotherapy were associated with poor prognosis in symptomatic obstructive colon cancer. Therefore, we suggest SEMS insertion as the first treatment modality for symptomatic obstructive colon cancer and adjuvant chemotherapy should be performed after surgery, especially when LN metastasis or vascular invasion is identified.

\section{NOTES}

\section{Ethical statements}

The study was performed in accordance with the ethical guidelines of the World Medical Association Declaration of Helsinki 2013. The study protocol was approved and monitored by the Institutional Review Board of the Ethics Committee of the College of Medicine, The Catholic University of Korea (No. XC14RIMI0056) and informed consent was wavied.

\section{Authors' contributions}

Conceptualization: JHB, YSL

Data curation: IKL, DSL, WKK, JHK, BHK, HMC, STO, SCL, YSL Statistical analysis, Visualization: $\mathrm{CHK}, \mathrm{JHB}$

Investigation: JHB, CSL, SRH, IKL, DSL, WKK, JHK, BHK, HMC, STO, SCL, YSL

Methodology: CHK, JHB, YSL

Project administration, Supervision: YSL

Writing-original draft: CHK

Writing-review \& editing: All authors

All authors read and approved the final manuscript.

\section{Conflict of interest}

All authors have no conflicts of interest to declare.

\section{Funding/support}

None.

\section{ORCID}

Chang Hwan Kim, https://orcid.org/0000-0003-0106-6012

Jung Hoon Bae, https://orcid.org/0000-0002-7598-2825

Chul Seung Lee, https://orcid.org/0000-0002-4859-3015

Seung-Rim Han, https://orcid.org/0000-0002-7362-3888

In Kyu Lee, https://orcid.org/0000-0001-9074-5214

Dosang Lee, https://orcid.org/0000-0002-1528-2317

Won Kyung Kang, https://orcid.org/0000-0002-3337-0644

Ji Hoon Kim, https://orcid.org/0000-0002-3093-1805

Bong-Hyeon Kye, https://orcid.org/0000-0002-5251-990X

Hyeon-Min Cho, https://orcid.org/0000-0002-7183-2838

Seong Taek Oh, https://orcid.org/0000-0002-5962-581X 
Sang Chul Lee, https://orcid.org/0000-0002-8681-7059

Yoon Suk Lee, https://orcid.org/0000-0002-1849-2774

\section{Supplementary materials}

Supplementary materials can be found via https://doi.org/10.7602/ jmis.2021.24.3.128.

\section{REFERENCES}

1. Katoh H, Yamashita K, Wang G, Sato T, Nakamura T, Watanabe M. Prognostic significance of preoperative bowel obstruction in stage III colorectal cancer. Ann Surg Oncol 2011;18:2432-2441.

2. Zhang Y, Shi J, Shi B, Song CY, Xie WF, Chen YX. Self-expanding metallic stent as a bridge to surgery versus emergency surgery for obstructive colorectal cancer: a meta-analysis. Surg Endosc 2012;26:110-119.

3. Dohmoto M, Hünerbein M, Schlag PM. Palliative endoscopic therapy of rectal carcinoma. Eur J Cancer 1996;32A:25-29.

4. Webster PJ, Aldoori J, Burke DA. Optimal management of malignant left-sided large bowel obstruction: do international guidelines agree? World J Emerg Surg 2019;14:23.

5. Pisano M, Zorcolo L, Merli C, et al. 2017 WSES guidelines on colon and rectal cancer emergencies: obstruction and perforation. World J Emerg Surg 2018;13:36.

6. van Hooft JE, van Halsema EE, Vanbiervliet G, et al. Self-expandable metal stents for obstructing colonic and extracolonic cancer: European Society of Gastrointestinal Endoscopy (ESGE) Clinical Guideline. Endoscopy 2014;46:990-1053.

7. Benson $\mathrm{AB}$, Venook AP, Al-Hawary MM, et al. NCCN guidelines insights: colon cancer, version 2.2018. J Natl Compr Canc Netw 2018;16:359-369.

8. Matsuda A, Miyashita M, Matsumoto S, et al. Comparison of longterm outcomes of colonic stent as "bridge to surgery" and emergency surgery for malignant large-bowel obstruction: a meta- analysis. Ann Surg Oncol 2015;22:497-504.

9. Choi JM, Lee C, Han YM, et al. Long-term oncologic outcomes of endoscopic stenting as a bridge to surgery for malignant colonic obstruction: comparison with emergency surgery. Surg Endosc 2014;28:2649-2655.

10. Kang SI, Oh HK, Yoo JS, et al. Oncologic outcomes of preoperative stent insertion first versus immediate surgery for obstructing leftsided colorectal cancer. Surg Oncol 2018;27:216-224.

11. Kye BH, Lee YS, Cho HM, et al. Comparison of long-term outcomes between emergency surgery and bridge to surgery for malignant obstruction in right-sided colon cancer: a multicenter retrospective study. Ann Surg Oncol 2016;23:1867-1874.

12. Kim MK, Kye BH, Lee IK, et al. Outcome of bridge to surgery stenting for obstructive left colon cancer. ANZ J Surg 2017;87:E245-E250.

13. Yamamoto $S$, Inomata $M$, Katayama $H$, et al. Short-term surgical outcomes from a randomized controlled trial to evaluate laparoscopic and open D3 dissection for stage II/III colon cancer: Japan Clinical Oncology Group Study JCOG 0404. Ann Surg 2014;260:23-30.

14. Papageorge CM, Zhao Q, Foley EF, et al. Short-term outcomes of minimally invasive versus open colectomy for colon cancer. J Surg Res 2016;204:83-93

15. Liu ZH, Wang N, Wang FQ, Dong Q, Ding J. Oncological outcomes of laparoscopic versus open surgery in pT4 colon cancers: a systematic review and meta-analysis. Int J Surg 2018;56:221-233.

16. Kye $\mathrm{BH}, \mathrm{Kim} \mathrm{JH}, \mathrm{Kim} \mathrm{HJ}$, et al. The optimal time interval between the placement of self-expandable metallic stent and elective surgery in patients with obstructive colon cancer. Sci Rep 2020;10:9502.

17. Sloothaak DA, van den Berg MW, Dijkgraaf MG, et al. Oncological outcome of malignant colonic obstruction in the Dutch Stent-In 2 trial. Br J Surg 2014;101:1751-1757.

18. Erichsen R, Horváth-Puhó E, Jacobsen JB, Nilsson T, Baron JA, Sørensen HT. Long-term mortality and recurrence after colorectal cancer surgery with preoperative stenting: a Danish nationwide cohort study. Endoscopy 2015;47:517-524.

19. Gorissen KJ, Tuynman JB, Fryer E, et al. Local recurrence after stenting for obstructing left-sided colonic cancer. Br J Surg 2013;100:18051809.

20. Sabbagh C, Browet F, Diouf $M$, et al. Is stenting as "a bridge to surgery" an oncologically safe strategy for the management of acute, left-sided, malignant, colonic obstruction? A comparative study with a propensity score analysis. Ann Surg 2013;258:107-115.

21. Arezzo A, Passera R, Lo Secco G, et al. Stent as bridge to surgery for left-sided malignant colonic obstruction reduces adverse events and stoma rate compared with emergency surgery: results of a systematic review and meta-analysis of randomized controlled trials. Gastrointest Endosc 2017;86:416-426.

22. Kim SJ, Kim HW, Park SB, et al. Colonic perforation either during or after stent insertion as a bridge to surgery for malignant colorectal obstruction increases the risk of peritoneal seeding. Surg Endosc 2015;29:3499-3506.

23. Malgras B, Brullé L, Lo Dico R, et al. Insertion of a stent in obstructive colon cancer can induce a metastatic process in an experimental murine model. Ann Surg Oncol 2015;22 Suppl 3:S1475-S1480.

24. van Hooft JE, Bemelman WA, Oldenburg B, et al. Colonic stenting versus emergency surgery for acute left-sided malignant colonic obstruction: a multicentre randomised trial. Lancet Oncol 2011;12:344-352.

25. Qwaider YZ, Sell NM, Stafford CE, et al. Adjuvant chemotherapy benefits on patients with extramural vascular invasion in stages II and III colon cancer. J Gastrointest Surg 2021;25:2019-2025.

26. Leijssen LG, Dinaux AM, Amri R, et al. Impact of intramural and extramural vascular invasion on stage II-III colon cancer outcomes. J Surg Oncol 2019;119:749-757.

27. Manceau G, Voron T, Mege D, et al. Prognostic factors and patterns of recurrence after emergency management for obstructing colon cancer: multivariate analysis from a series of 2120 patients. Langenbecks Arch Surg 2019;404:717-729. 